CPE

4,1

86

Received 10 March 2021

Revised 22 April 2021

Accepted 28 June 2021

\section{China's poverty alleviation "miracle" from the perspective of the structural transformation of the urban-rural dual economy}

\author{
Fan Gao \\ School of Economics, Fudan University, Shanghai, China
}

\begin{abstract}
Purpose - Poverty alleviation has been a major theme of China's modernization process since the founding of New China. This paper points out that China's poverty alleviation process presents three stylized facts: "Miraculous" achievements of poverty alleviation have been made on a global scale; the poverty alleviation achievements mainly occurred in the high growth stage after reform and opening up; the poverty alleviation process is accompanied by the structural transformation of the urban-rural dual economy.

Design/methodology/approach - Therefore, a logically consistent analytical framework should form among the structural transformation of the dual economy, economic growth and the achievements in poverty alleviation. In logical deduction, the structural transformation of the dual economy affects rural poverty alleviation through the effects of labor reallocation, agricultural productivity improvement, demographic change and fiscal resource allocation.

Findings - The first two refer to economic growth, and the latter two are alleviation policies. The combination of economic growth and poverty alleviation policies is the main cause for poverty alleviation performance. China's empirical evidence can support the four effects by which the structural transformation of the dual economy affects poverty alleviation.

Originality/value - China's socialist system and its economic system transformation after reform and opening up provide an institutional basis for the effects to come into play. After 2020, China's poverty alleviation strategies will enter the "second-half" phase, namely, the phase of solving the problems of relative poverty in urban and rural areas by adopting conventional methods and establishing long-term mechanisms. This requires the facilitation of the reconnection between poverty alleviation strategies and the structural transformation of the dual economy in terms of development ideas and policy directions.
\end{abstract}

Keywords Poverty alleviation strategies, Structural transformation of urban-rural dual economy, Labor reallocation effects, Economic system transformation

Paper type Research paper

\section{Introduction}

Since the reform and opening up, China has created a "miracle" of economic growth worldwide. According to the data from the World Bank, China's per capita GDP calculated in current US dollars increased from 156.40 US dollars to 9,770.85 US dollars from 1978 to 2018, and in the 2010 constant US dollars, it grew from 307.09 US dollars to 7,752.56 US dollars. China has evolved from a typical low-income country into an upper-middle-income country with the world's largest population. China's economic growth has been coupled with a considerable decline in the poor population, especially within the rural areas. According to the

(C) Academic Monthly. Published in China Political Economy. Published by Emerald Publishing Limited. This article is published under the Creative Commons Attribution (CC BY 4.0) licence. Anyone may reproduce, distribute, translate and create derivative works of this article (for both commercial and noncommercial purposes), subject to full attribution to the original publication and authors. The full terms of this licence may be seen at http://creativecommons.org/licences/by/4.0/legalcode. Originally published in Simplified Chinese in Economic Research Journal.

This paper received funding from the National Social Science Foundation (grant agreement No. 17ZDA066). 
current poverty standard (2,300 yuan per person per year, constant price in 2010), China's rural poor population dropped from 77.39 million in 1978 to 5.51 million people in 2019, with the poverty rate dropping from 97.5 to $0.6 \%$. Such poverty alleviation performance can be called a "miracle" in China's history and even worldwide. Cai (2019) commented that since the reform and opening up, China had achieved the world's fastest economic growth, improved people's living standards to the greatest extent and realized the world's enormous poverty alleviation. According to Wang (2020), it has never been possible for so many poor people to throw off poverty in such a short period of human history. This is the most outstanding poverty alleviation achievement made in a short period in human history, which has stricken the world's attention. China's poverty alleviation performance is even more prominent than its growth performance. Wang et al. (2020) also praised that if China's high-speed economic growth was regarded as a miracle, China's poverty alleviation achievement could be hailed as a miracle in a miracle.

China has achieved rapid economic growth and large-scale poverty alleviation, realizing the dual development goals of "efficiency" and "fairness" to a certain extent. So, why can China achieve both "fairness" and "efficiency"? How can China achieve the conspicuous poverty alleviation performance in the context of economic growth and even generate a "miracle" of poverty alleviation that is more outstanding than economic growth achievements? These questions need to be answered clearly in terms of the theoretical and practical levels. Answering the questions will help comprehend the implementation logic of China's localized poverty alleviation strategies and provide other countries with "Chinese experience" and "Chinese wisdom" in poverty alleviation. As the world's most populous developing country, China has had an urban-rural dual economic structure for a long time. Tan (2018) pointed out that China's basic social structure so far was still an urban-rural dual economic structure. Likewise, Xing and Li (2018) asserted that the most basic social structure that affected poverty was the urban and rural dual economic structure for contemporary China. To enhance the structural transformation of the dual economy based on its conditions is a central theme for China in realizing socialist modernization. The structural transformation of the dual economy is a process of increasing the efficiency of resource allocation and thus facilitating economic growth as well as a process of changing the income distribution and living conditions of urban and rural residents. Therefore, it is a significant and feasible idea to explain China's poverty alleviation "miracle" from the perspective of the structural transformation of the dual economy. Based on the basic stylized facts of China's poverty alleviation, this paper focuses on exploring the theoretical mechanism and empirical evidence of the structural transformation of the dual economy affecting China's poverty alleviation performance. Based on this, the "reconnection" ideas and policy options of poverty alleviation strategies and the structural transformation of the dual economy after 2020 can be deduced. It is emphasized in this paper that the structural transformation of the dual economy is the fundamental reason for China's achieving "efficiency" and "fairness", especially the achievement of the "miracle" of poverty alleviation since the reform and opening up. In the "next phase" of China's poverty alleviation, the structural transformation of the dual economy still needs to be accelerated continuously.

\section{China's poverty alleviation "miracle" and its basic stylized facts}

The establishment of the People's Republic of China in 1949 marked the beginning of the construction of socialist modernization in China under the leadership of the Communist Party of China. After the establishment of the People's Republic of China, China accelerated economic and social changes through land reform, the "Three Great Remolding Movements" of socialism, and the strategy of prioritizing the development of heavy industry, formulating the economic operation mechanism with public ownership as the mainstay of the economy as 
CPE 4,1

well as the characteristic of mandatory planning in terms of productive relations, and an independent and relatively complete industrial system and national economic system in terms of productivity. However, the planned economic system before 1978 restricted the improvement of economic efficiency and residents' living conditions. Until the end of the 1970s, China was still a low-income country with a large population with the absolute and relative numbers of the rural poor population at a high level. Since 1978, China has improved the transformation of the economic system under the premise of adhering to the socialist system, thereby achieving sustained and rapid economic growth. This has enhanced China's financial strength, overall national strength and global influence with rural poverty alleviation also entering "a fast lane". After the different stages of agrarian economic system reform promoting poverty relief (1978-1985), development-oriented poverty alleviation (1986-2010), and targeted poverty alleviation (since 2011), both the absolute numbers and relative numbers of China's rural poverty population have dropped significantly. Based on the history of development since the establishment of New China, it can be found that China's poverty alleviation process presents three basic stylized facts as follows.

\subsection{Stylized fact 1: "Miraculous" achievements have been made in poverty alleviation on a global scale}

China is the world's most populous developing country, and its poverty alleviation progress is a vital part of the cause of global anti-poverty. One should observe the characteristics of China's poverty alleviation from the dimension of cross-country comparison. According to "Poverty and Shared Prosperity 2018: Piecing Together the Poverty Puzzle" released by the World Bank in October 2018, three standards for the level of expenditure per person per day calculated based on the 2011 purchasing power parity (PPP) are given: US $\$ 1.9$, US\$3.2 and US\$5.5, which correspond to the poverty lines of low-income countries, lower-middle-income countries and upper-middle-income countries, respectively. Based on this classification standard, China's poverty alleviation performance under the context of globalization can be explored from two aspects: the perspective of absolute numbers and the perspective of relative numbers. In terms of absolute numbers, according to the poverty line of US $\$ 1.9$ from 1990 to 2015 retrieved from the data of World Bank, China's poor population dropped from 751.8 million to 10 million, and the world's poor population decreased from 1.8893 billion to 736.7 million. China's contribution to the world's total poverty alleviation is $63.81 \%$. Based on the poverty line of 3.2 US dollars, China's poor population has fallen from 1.0219 billion to 95.5 million, the world's poor population has dropped from 2.9203 billion to 1.9365 billion and China's contribution degree climbed to $94.17 \%$. Based on the poverty line of 5.5 US dollars, China's poor population has dropped from 1.11159 billion to 372.8 million, the world's poor population has decreased from 3.5461 billion to 3.3865 billion and China's contribution degree has incredibly reached $465.60 \%$.

Regarding relative numbers, the poverty incidence rate reflected the proportion of the poor population in the total population. As shown in Table 1, according to the poverty lines of 1.9 US dollars, 3.2 US dollars and 5.5 US dollars from 1990 to 2016, China's poverty incidence rate decreased from 66.2 to $0.5 \%$, from 90.0 to $5.4 \%$ and from 98.3 to $23.9 \%$, respectively. The decline degree of China far exceeded those of lower-middle-income countries, upper-middleincome countries and the world. Taking the poverty line of 1.9 US dollars as an example, the incidence of poverty in China declined by 65.5 percentage points from 1990 to 2015, far exceeding the decline of 30.9 percentage points in lower-middle-income countries, 39.0 percentage points in upper-middle-income countries and 26.0 percentage points in the world in the same period. Poverty depth is also a relative indicator that reflects the progress of poverty alleviation in a specific country. As shown in Table 2 , based on the poverty lines of US $\$ 1.9, \$ 3.2$ and $\$ 5.5$, China's poverty depth fell from 24.1 to $0.1 \%$, from 47.0 to $1.0 \%$ and 


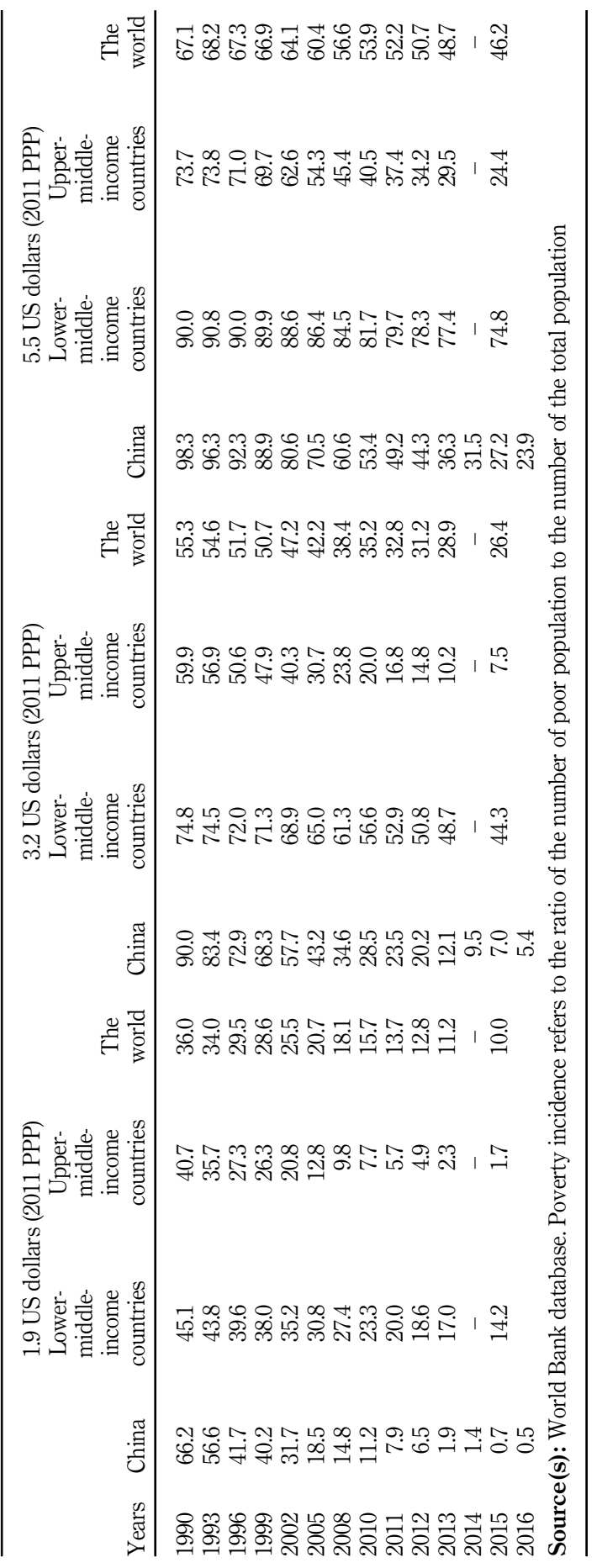

China's poverty alleviation

89

Table 1. International comparisons of changes in the incidence of poverty in China (\%) 
CPE

4,1

90

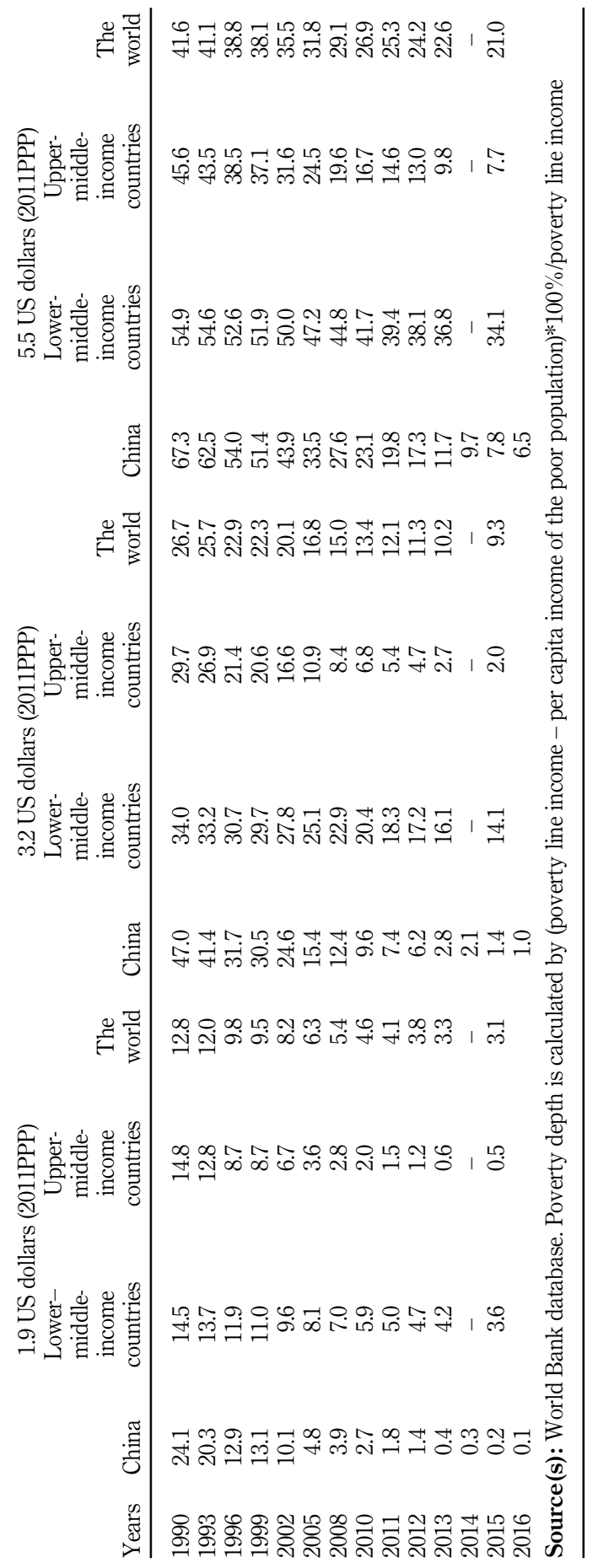

Table 2.

International comparisons of changes in China's poverty depth (\%) 
from 67.3 to $6.5 \%$ from 1990 to 2016 between 1990 and 2016, respectively, which exceeded the decline in lower-middle-income countries, upper-middle-income countries and the world. Taking the poverty line of 1.9 US dollars as an example, China's poverty depth dropped by $24.0 \%$ from 1990 to 2015, while that of the lower-middle-income countries, upper-middleincome countries and the world declined by $10.9 \%, 14.3 \%$ and $9.7 \%$, respectively. In China, hundreds of millions of people shook off poverty within a relatively short period. This is a "miraculous" achievement in the history of human development and an irreplaceable contribution to the cause of overall poverty alleviation worldwide.

\subsection{Stylized fact 2: the achievement of poverty alleviation mainly occurred in the high- economic-growth stage after the reform and opening up}

Understanding China's poverty alleviation requires a "spatial" perspective of globalization and a "historical" perspective of the evolution of Chinese society. The implementation of reform and opening up in 1978 was a significant turning point in China's modernization process. It divided China's development history of more than 70 years since the establishment of New China into two successive but distinctive stages. The economic differences between these two stages lie in the economic system and economic growth rate. Before 1978, China implemented a planned economic system characterized by a high degree of government centralization with the economic growth rate relatively low and incredibly volatile. According to the data provided by CEIC Data Global Database (CEIC), the average annual GDP growth rate in China was $6.50 \%$ from 1953 to 1977 , and the average annual growth rate of GDP per capita was $4.32 \%$, with their coefficients of variation being 1.6093 and 2.2588 , respectively. After 1978, China gradually transformed the planned economic system into a socialist market economic system. Under the background of system transformation, China's economic growth performance has undergone profound changes. From 1978 to 2019, the average annual growth rates of GDP and GDP per capita in China were 9.45 and $8.44 \%$. The coefficients of variation were 0.2864 and 0.3140 , respectively. After the reform and opening up, the Chinese economy has demonstrated a faster and more stable growth trend. As shown in Table 3, China's GDP per capita increased from 385 yuan to 70,892 yuan from 1978 to 2019 . According to the average exchange rate, the GDP per capita in 2019 reached 10,276 US dollars, exceeding 10,000 US dollars for the first time, and approaching "the threshold line" of the high-income countries-12,375 US dollars.

After establishing New China, the Chinese Communist Party's leadership in modernization and the socialist system's pursuit of shared prosperity provide the political, organizational and ideological foundation for China's poverty alleviation. As a developing country with a large population and a vast territory, China has different development strategies, economic systems and development performances in different periods, accompanied by exceptional poverty alleviation performances. Comparatively, China's large-scale poverty alleviation mainly occurred in the high-economic-growth stage after 1978. As shown in Table 3, according to the poverty line standard in 1978, China's rural poor population declined from 250 million to 14.79 million from 1978 to 2007, with the poverty incidence rate dropping from 30.7 to $1.6 \%$. According to the poverty line standard in 2010 , the number of rural poor people fell from 770.39 million to 5.51 million from 1978 to 2019 , and the poverty incidence rate decreased from 97.5 to $0.6 \%$. In 1978, China's population and its rural population were 960.29 million and 790.14 million, respectively. Based on the poverty line standard in 2010, the vast majority of the rural population were poor at the initial stage of reform and opening up. There was no significant decline in the poor population during the planned economy era. It was only after 1978 that there was a massive reduction in the number of the poor. According to the poverty lines of 1.9 US dollars, 3.2 US dollars and 5.5 US dollars set by the World Bank, China's impoverished population reached 751.8 million, 1.0219 billion 
$\mathrm{CPE}$
4,1

92

Table 3.

Changes in the poverty situation in China's rural areas from 1978 to 2019

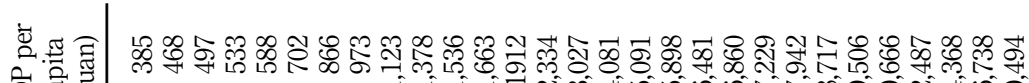

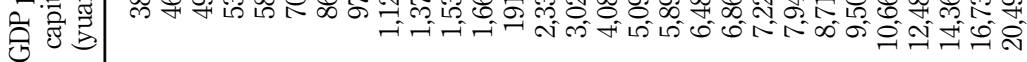

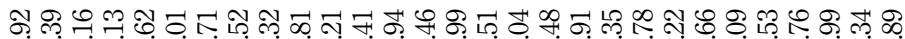

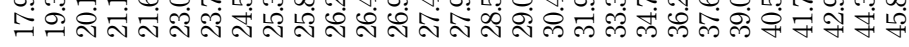

$$
\text { (⿹ }
$$

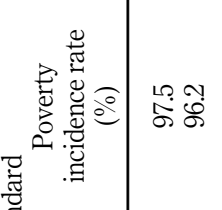

$\stackrel{\substack{\infty \\ \infty}}{\infty}$

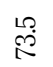

$\stackrel{10}{8}$

$\stackrel{\infty}{\mathfrak{g}}$

กิ่

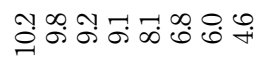

$\begin{array}{ll}5 & 0 \\ 0 & 0 \\ 8 & 0 \\ 8 & 0\end{array}$

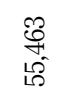

ญี

है

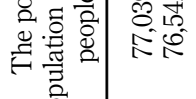

ถે

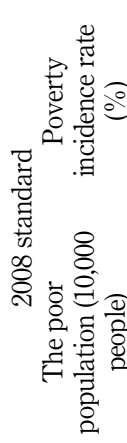

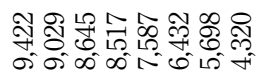

焉莺

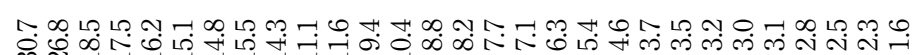

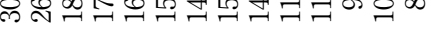

:

焉

क

$\infty$

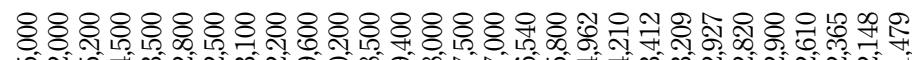

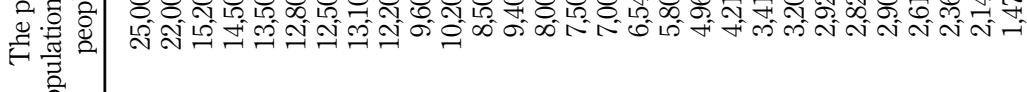
ڤั

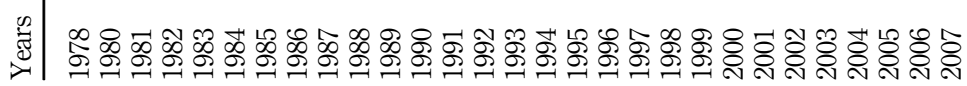




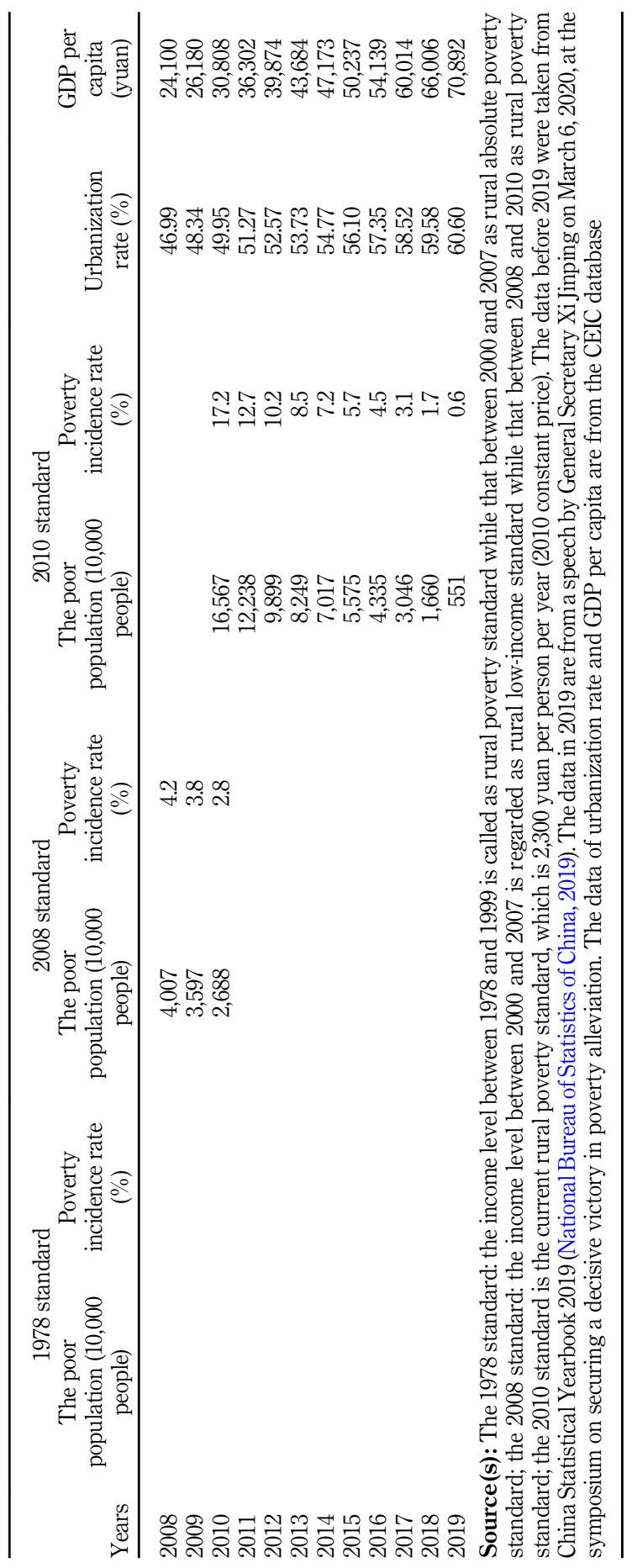

China's
poverty
lleviation

93

Table 3. 
CPE 4,1

and 1.11159 billion in 1990. In the same year, China's total population was 1.1433 billion. Even in the early 1990s, according to the World's Bank standards, the vast majority of China's people were still lacking, and the large-scale poverty alleviation occurred in the stage of high economic growth after 1990.

\subsection{Stylized fact 3: the process of poverty alleviation is accompanied by the structural transformation of the urban-rural dual economy}

In addition to the temporal and spatial dimensions, the exploration of poverty alleviation in China should also focus on the "structural" changes in the economy and society. Notably, urban and rural areas are the two major sectors of the national economy, and the urban-rural dichotomy is an essential structural feature of developing countries. As a developing country, China has also had a dual structural feature for a long time. This feature was even consolidated and strengthened during the planned economy due to the people's commune system, the household registration system and the unified purchase and sale system of agricultural products. Since 1978, China's dual structure has presented a basic trend of continuous transformation, and the urban-rural economic relationship has also entered the stage of integration from the fragmented state (Gao, 2019). The poverty alleviation performance is closely related to such structural change. The structural transformation of China's dual economy manifests itself in output value, employment and the transformation of demographic structure. From 1978 to 2019, the proportion of the value-added of the primary industry concentrated in rural areas declined from 27.69 to $7.11 \%$, with agriculture showing a clear trend of "small-sectorization", and the dependence of economic growth on the secondary and tertiary industries tended to increase. During this period, with the proportion increasing from 23.69 to $57.11 \%$, urban employment became the mainstay of China's labor force employment. In terms of population structure, as shown in Table 3, the proportion of urban permanent residents increased from 17.92 to $60.60 \%$ from 1978 to 2019 . China has evolved from a country dominated by rural employment and population to a country dominated by urban employment and population. The evolution of output value, employment and population structure implies the increase in industrialization rate and urbanization rate, and the structural transformation of the dual economy. This is the most typical structural change that has occurred in China after the reform and opening up. As large-scale poverty alleviation mainly occurred after the reform and opening up and poverty alleviation depends on the behavioral logic of the rural population and national policies, China's poverty alleviation should be inherently related to the structural transformation of the dual economy. To understand the "miracle" of poverty alleviation, we should note such a stylized fact that the "miracle" is accompanied by the structural transformation of the dual economy.

\section{The impact mechanism of structural transformation of urban-rural dual economy on poverty alleviation performance}

China has created a "miracle" of poverty alleviation, which is accompanied by economic growth and the structural transformation of the urban-rural dual economy. To explain the mechanism of poverty alleviation occurrence in China, we should note its inherent relationship with economic growth and changes in urban-rural relations to have a deep understanding of the origin and the direction of poverty alleviation in China. There are three interpretive clues in the academic circle regarding China's poverty alleviation performance since the reform and opening up. The first one is to stress the significant impact of economic growth, especially labor mobility, on poverty alleviation. For example, Zhou and Tao (2016) emphasized that "population mobility was the most effective way to reduce poverty" by evaluating the effect of government investment in poverty alleviation. Fan and Jiang (2016) 
found in their research that labor mobility improved the absolute income of rural households and also reduced the relative probability of being poor. Wang et al. (2018) also found that the non-agricultural transfer of China's agricultural labor significantly reduced poverty and played a crucial role in poverty alleviation of rural areas. Zhang and Luo (2018) found that the deregulation of rural human resources and land property rights promoted the incentive and diffusion effects of factor flow, which was the most important reason for the large-scale poverty alleviation in rural China. Wang (2008) emphasized that the main driving force for large-scale poverty alleviation was economic growth, especially the continuous growth of agriculture and rural economy. The economic growth of agriculture and rural areas was achieved by a series of reform and opening-up measures, the constant accumulation of workforce and material capital and continuous technological progress. The second one is to emphasize the critical role of government policies, especially the governments' targeted poverty alleviation policies, in poverty alleviation. For example, Wang and Xu (2019) discovered that China's targeted poverty alleviation policies had a significant poverty alleviation effect. The poverty alleviation policies had remarkably increased the net household income per capita and reduced the incidence rate of poverty. Zhang and Zhou (2019) asserted that the targeted poverty alleviation policies had significantly increased the net gains and transfer payment incomes of poor households. In this regard, Lu and Du (2019) found that China's fiscal redistribution tool significantly affected poverty alleviation. Fiscal redistribution had reduced the breadth, depth and intensity of poverty throughout China by more than $20 \%$. The third one is to emphasize the joint effects of economic growth and poverty alleviation and development policies. For example, Wang (2018) believed that China's achievement of large-scale poverty alleviation resulted from its rapid economic growth and the implementation of poverty alleviation and development. Wang (2017) also found that economic growth was the dominant factor in China's poverty alleviation performance, but with the rebound of the poverty rate and the poverty gap rate, the contribution rate of income distribution and redistribution factors in poverty alleviation would rise.

The above three clues are helpful for people to understand the logic of poverty alleviation in China. They explain the reasons for the formation of the poverty alleviation performance from the perspectives of the market, government and market-government combination. However, China is a developing country with dual urban-rural characteristics, and rural poverty accounts for the central part of the overall poverty. Li et al. (2018) believed that the mainline of economic growth and farmers' income increase couldn't be bypassed whatsoever from any perspective China's poverty alleviation over the past 40 years is explained. Therefore, these clues need to be further questioned. For example, how has China's economic growth been achieved since the reform and opening up? What is the relationship between economic growth and the structural transformation of the dual economy? What conditions are needed for China to implement poverty alleviation policies, primarily targeted poverty alleviation policies? Why were the large-scale poverty alleviation policies not implemented in the early stages of reform and opening up? Economic growth and poverty alleviation policies constitute two forces that enhance large-scale poverty alleviation. Under what conditions can the two be organically combined, and how does the structural transformation of the dual economy affect the combination of economic growth and poverty alleviation policies? To find out the answers to these questions, we should take the stylized facts of the poverty alleviation process as the basis and constitute a logically self-consistent analysis framework among the structural transformation of the dual economy, economic growth and achievements of poverty alleviation. In summary, since the reform and opening-up, China's large-scale poverty alleviation has resulted from the combined effects of economic growth and poverty alleviation policies. However, both economic growth and poverty alleviation policies have occurred in the structural transformation of the dual economy. Such transformation makes 
CPE 4,1

\section{6}

Figure 1.

The main impact mechanism of the structural transformation of the urban-rural dual economy on poverty alleviation them successively related and organically integrated. It is inaccurate to understand China's poverty alleviation issues without the most specific structural change- the structural transformation of the dual economy. Based on this, the internal mechanism of the structural transformation of the dual economy facilitating rural poverty alleviation can be put forward, which is depicted in Figure 1.

In Figure 1, the urban-rural dual structural opposition exists in particular countries, which manifests itself in multiple dimensions such as industries, productivity, social security resource allocation and the distribution of the poor population. The rural areas are dominated by the primary sector, with low productivity labor, less access to formal social security resources and a vast majority of the poor population. In contrast, cities are dominated by secondary and tertiary industries, with generally high labor productivity, more access to formal social security resources and relatively few poor people. In this context, the main task of the poverty alleviation strategy is to eliminate the rural poor population on a large scale. In the context of the solidification of the dual structure, achieving this goal of poverty alleviation is a natural and slow process accompanied by the development of a single rural sector. However, under the circumstance of the structural transformation of the dual economy, the rural poor population will obtain an improvement in their income and living conditions due to various urban-rural interaction mechanisms and are expected to get rid of the previous absolute poverty or relative poverty. The structural transformation of the dual economy first manifests itself as follows: There is a gap in labor productivity between urban and rural areas, and the labor productivity and wages of labor in rural areas are generally lower than those in cities; once wages can reflect the relative scarcity of factors in different sectors, and there are no institutional barriers to labor mobility, the rural labor force will flow to cities spontaneously on a large scale, and integrate with the factors like capital to obtain higher labor productivity and wages. This forms the first effect of the dual structural transformation

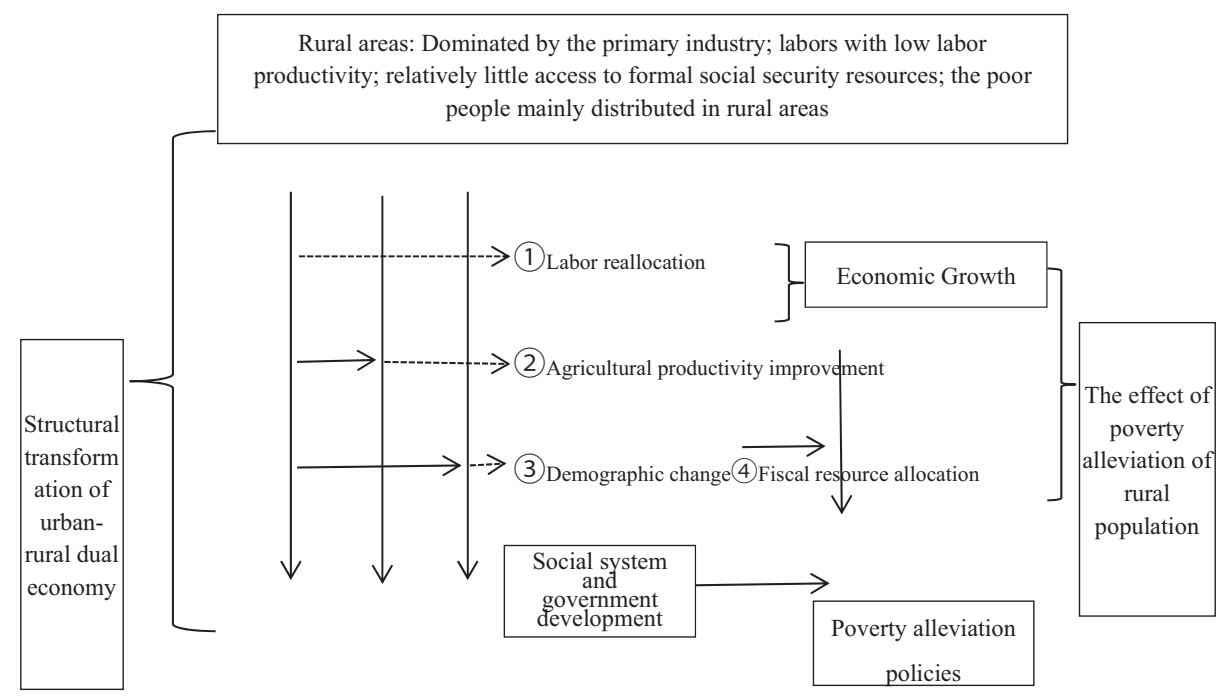

Cities: Dominated by secondary and tertiary industries; relatively high labor productivity; relatively more access to formal social security resources; relatively small poor population 
on poverty alleviation - the effect of labor reallocation, which is the process of increasing the income level of rural labor at the micro-level as well as the process of improving efficiency and thus economic growth at the macro-level. Moreover, non-agricultural labor mobility and other factors will generate another two effects and drive poverty alleviation in rural areas. First, the structural transformation of the dual economy not only means non-agricultural labor mobility in rural areas but also means the close interaction between the urban and rural product markets; that is, the product supply mode and industrial structure in rural areas change according to the needs of urban residents. Therefore, the traditional economic model in rural areas dominated by the primary industry turns into a modern model in which the three sectors are integrated and the added value continues to increase. Furthermore, the redistribution of urban and rural labor forces has also led to changes in the rural man-land relationship, supporting changes in the rural product supply and industrial patterns. In this way, the structural transformation of the dual economy has formed the second effect on poverty alleviation - the effect of agricultural productivity improvement, which is particularly significant for improving the living conditions of the remaining rural population. Second, the structural transformation of the dual economy is not only the nonagricultural flow of rural labor but also a trend change in the structure of urban and rural populations. With the rural laborers flowing to cities on a large scale, some laborers will bring their families to work and live in cities and even turn into urban residents through their efforts. Some cities also open up employment and social integration space for the rural population. In a nutshell, the structural transformation of the dual economy is accompanied by an increase in the urbanization rate of the people and thus forms the third effect on poverty alleviation: the effect of demographic changes. This effect allows the rural population to share the benefits of growth brought about by urbanization and facilitates the evolution of the urban-rural demographic structure, causing the proportion of the rural population to decrease and the poor population to be an easier target, which provides full support for the gradual inclination of financial resources to rural areas and impoverished rural population.

Among the above three effects, labor reallocation enables rural residents to obtain higher economic returns than from agriculture through the cross-sectoral, cross-industry and crossregional mobility of labor based on the market signals. The effect of agricultural productivity improvement enables the labor force remaining in the rural areas to obtain higher economic returns due to the change in the combination of factors and the transformation of the industrial structure. These two factors constitute the core mechanism for large-scale poverty alleviation in rural areas. Notably, the effects of labor reallocation and the agricultural productivity improvement mean that labor, land, capital and the other factors have formed new combinations due to the increased mobility of labor, land and capital under the influence of the market mechanism, which will stimulate and release a huge growth potential at the macro-level. Economic growth in developing countries is usually a process of dual structural transformation and generation of the effects of labor redistribution effect and agricultural productivity improvement. Economic growth leads to a "bigger pie". With growth comes the enhancement of national fiscal mobilization ability, which provides the material basis for the government to "distribute the pie" and implement more fairness-oriented transfer payments. However, the material base is not equivalent to the government's inevitable implementation of poverty alleviation policies. Only the combination of the material basis and the other two forces can cause the government to adopt a fiscal allocation method that favors the poor population. One of the forces is the demographic change effect mentioned earlier. With the structural transformation of the dual economy, the population structure has shown a trend of increased urbanization rate and decreased percentage of the rural population. The labor mobility associated with the structural transformation of the dual economy also acts as a "screener", that is, labor with the higher endogenous ability is often more qualified to choose non-agricultural mobility. With that as a reference, the governments can accurately identify 
CPE 4,1

98

rural poor population caused due to regional and individual reasons. This makes the governments more capable of targeting "small-sectoral" rural groups, as well as the regional and individual rural poor people, thus implementing inclined fiscal transfer payments to solve the poverty problem. The other force is the structural transformation of the dual economy. Together with the accompanying economic growth, it can enable most rural residents to share the fruits of economic growth. Still, it can hardly ensure that all rural lowincome people obtain simultaneous improvement in their living standards. In fact, because of the issues such as system transformation and individual factors, income distribution problems may become more prominent, and some rural populations may still be plagued by absolute poverty or relative poverty. In this context, social systems, development concepts and government policies play an essential role in poverty alleviation performance. Countries guided by the pure pursuit of economic growth will tolerate the widening of the income distribution gap by the logic of market selection, and their measures to solve the poverty problem are basically without merit. However, countries directed by the goal of pursuing the development of productivity and common prosperity will put resolving the imbalance of development in a more critical position in the context of the structural transformation of the dual economy driving economic growth, and meanwhile rely on the state power to place more financial resources after growth on the rural poor people to achieve large-scale poverty alleviation performance. In this sense, the structural transformation of the dual economy forms the fourth effect for poverty alleviation: the effect of financial resources allocation. This effect depends on not only the effects of economic growth and demographic changes brought about by the structural transformation of the dual economy but also the country's social system, development concepts and policy arrangements. Apparently, only the organic combination of economic growth and poverty alleviation policies can ultimately lead to a large-scale decline in the rural poor population, and economic growth and poverty alleviation policies are closely related to the structural transformation of the dual economy. Besides, the poverty alleviation policies can only be effectively implemented in the case of economic growth, changes in population structure and emphasis of shared concept.

\section{Empirical evidence of the structural transformation of the dual economy promoting China's poverty alleviation}

The structural transformation of the urban-rural dual economy affects poverty alleviation performance via the effects of labor reallocation, agricultural productivity improvement, demographic change and fiscal resource allocation. The first two correspond with economic growth, and the latter two mean poverty alleviation policies. The succession and integration of poverty alleviation policies and economic growth are the fundamental reason for poor people to shake off poverty on a large scale. This provides a theoretical basis for a profound understanding of how the "miracle" of poverty alleviation happened in China. From a practical perspective, the forgoing influence mechanism can be strongly supported by China's empirical evidence.

Regarding the effect of labor redistribution, marked by the implementation of "large contract management" in Xiaogang Village, Anhui Province in 1978, China's rural economic system has begun to shift from a people's commune system to a household contract responsibility system with remuneration linked to output. As a result, farmers' enormous agricultural production vitality was spurred due to the acquisition of contracted rights for land management, and the rural labor forces were socially reallocated due to the obtainment of the autonomy of labor use. In this context, the trend of large-scale and continuous nonagriculturalization of rural labor has emerged. The separation between urban and rural areas and the compulsory barriers between commodities and factors were removed. China started the structural transformation of the dual economy with labor mobility as the core mechanism. 
Since 1978, the redistribution of labor in China's urban and rural areas has been reflected in the structural changes in the number of employment between urban and rural areas as well as various industries. According to data from CEIC, the proportion of rural employment in China fell from 76.31 to $44.04 \%$ between 1978 and 2018, an average annual decrease of 0.79 percentage points, which exceeded the average annual drop of 0.43 percentage points from 1952 to 1977. After 2014, the employment pattern in China has been dominated by urban workers rather than the previous mainstay, the rural workers. During the same period, the proportion of the primary industry in rural employment declined from 92.43 to $59.29 \%$, with an average annual decrease of 0.81 percentage points. The employment of rural labor has shown a trend of significant pluralism and diversification. The rural labor force first flowed to the localized non-agricultural industries within the rural areas, which was embodied by the rapid increase in employment in township and village enterprises. From 1978 to 1996, the number of employees in the township and village enterprises increased from 28.27 million to 135 million. After the mid-1990s, with a loosened household registration system and the development of private enterprises and foreign-funded enterprises, the rural labor force began to move to the urban areas and other regions, manifested by the rapid increase of peasant workers, especially migrant workers. At the end of 2019, the number of peasant workers and migrant workers reached 291 million and 174 million. The employment of peasant workers is mainly concentrated in the industries of manufacturing, construction and urban life services.

In the market economy, the rural labor constantly shifts from low-productivity sectors to high-productivity sectors, from low-income sectors to high-income sectors, which promotes economic growth at the macro-level and the increase in the income level of laborers at the micro-level. The structural transformation of China's dual economy and rural labor transfer has also led to economic growth at the macro-level. Studies have shown that rural labor mobility was an important source of China's economic growth (Hao, 2016; Cheng et al., 2018). At the micro-level, the flow of rural labor has profoundly changed farmers' income level and structure. In the context of labor force redistribution, the income of the Chinese farmers has three fundamental characteristics. First, their income level shows a rapid growth trend. According to China Statistical Yearbook 2019 (National Bureau of Statistics of China, 2019), the per capita disposable income of farmers increased from 133.6 yuan to 14,617.0 yuan from 1978 to 2018. Setting the per capita disposable income in 1978 as 100, the farmers' per capita disposable income index in 2018 would be 1945.3, which exceeded that of the urban residents $(1,627.6)$ of the same period. Second, the original household-business-income-dominated income structure has become wage-and-salary-dominated. Since 1978, along with the nonagricultural migration of rural labor, the proportion of wage and salary in farmers' income has been increasing, while the proportion of household business income has been declining. According to data provided by CEIC, from the perspective of farmers' per capita net income, the proportion of wage and salary increased from 18.56 to $45.25 \%$ from 1983 to 2013 , and the proportion of household business income dropped from 73.50 to $42.64 \%$. Regarding farmers' per capita disposable income, the proportion of wages and salary increased from 38.7 to $41.0 \%$ from 2013 to 2018 , and the ratio of net business income declined from 41.7 to $36.7 \%$. After 2015, in place of net business income, wages and salary became the primary source of per capita disposable income of farmers. Third, the dependence of farmers' net business income on the primary industry (agriculture, forestry, animal husbandry and fishery), especially agriculture, has gradually tended to decrease. From 2013 to 2018, the proportion of net business income in per capita disposable income of farmers declined from 41.7 to $36.7 \%$. As the net business income of the secondary industry was relatively stable and that of the tertiary sector increased, the decline in the proportion of net business income mainly resulted from the ratio of the net business income of the primary industry, that is, a decline from 30.1 to $23.9 \%$. Among others, the proportion of agriculture fell from 22.9 to $17.8 \%$. In summary, the 
CPE 4,1

structural transformation of China's dual economy since 1978 has first manifested itself as the non-agricultural flow of the rural labor force, which has led to rapid economic growth, increased farmers' income level and changes in the income structure. This shows that the effect of labor redistribution is prominent. Especially, the increased proportion of wages and salary indicates that the structural transformation of the dual economy is an essential motive for the significant improvement of farmers' incomes.

In terms of the effect of agricultural productivity improvement, agriculture is usually the first industry that rural laborers engage in. Improving agricultural productivity can increase farmers' business incomes, expand rural laborers' choices between urban and rural areas and among industries, thus becoming an essential mechanism for driving economic growth and improving farmers' living standards. From the perspective of the relationship between agricultural productivity and poverty alleviation, compared with other rural residents, the rural poor people are more dependent on farming operations. According to Poverty Monitoring Report of Rural China 2019, in 2018, the proportion of employees in the primary industry in China's rural poverty-stricken areas was $66.3 \%$, which was higher than that in the overall rural areas $(55.8 \%)$. In 2018 , the net business income and the net business income of the primary industry accounted for 36.7 and $23.9 \%$ of farmers' per capita disposable income, respectively, and also accounted for 37.5 and $26.9 \%$ of farmers' per capita disposable income in poverty-stricken areas, respectively. It can be seen that industrial development has provided a direct driving force for China's large-scale poverty alleviation (Poverty Alleviation Research Group of National Institute of Development Strategy at Wuhan University, 2019), and the growth of the primary industry, which is dominated by agriculture, has played a more outstanding role in poverty alleviation (Wang, 2008; Ravallion and Chen, 2007). From 1978 to 2018, the labor productivity of China's primary industry (the value-added of the primary industry/employees in the primary industry) increased from 359.65 yuan per person to $31,960.32$ yuan per person, showing a growth speed faster than the increase from 198.01 yuan per person to 321.13 yuan per person from 1952 to 1977. Since the reform and openingup, China's agricultural labor productivity has witnessed a rapid growth trend, enabling the farmers to acquire higher agricultural business incomes and thus have the opportunity to get rid of the previous poverty on a large scale.

The increase in agricultural labor productivity can only be fully realized with the structural transformation of the dual economy. In the case of structural transformation of dual economy, the demand of urban residents provides a driving force for rural product supply and industrial transformation so that the farmers can gain benefits due to the increase in the added value of their products and the returns on investment. Since the reform and opening-up, China's agricultural industrial structure has undergone significant changes. That is, it has shifted from planting domination to the all-around development of agriculture, forestry, animal husbandry and fishery, with a shift of the planting subindustry from crop planting to the coordinated development of food crops, cash crops and forage crops. According to the data provided by CEIC, between 1978 and 2018, the proportion of agricultural output value in the output value of agriculture, forestry, animal husbandry and fishery fell from 79.99 to $54.11 \%$, with that of animal husbandry increased from 14.98 to $25.27 \%$, and the proportion of fishery rising from 1.58 to $10.68 \%$. In addition, the proportion of the sown area of food crops in the total crop sown area fell from 80.33 to $70.55 \%$ while the that of cash crops and specialty crops is increasing. In the context of the structural transformation of the dual economy, the man-land relationship in the rural areas has further changed. The combination of agricultural factors has been further optimized. Agricultural operations have gradually moved toward a new state of a moderate scale and intensive use of capital and technology, which also supports the increase in agricultural productivity. From 1978 to 2018, the per capita sown area of crops in the primary industry increased from 7.95 $\mathrm{mu} /$ person to $12.28 \mathrm{mu} /$ person. According to the third national agricultural census data, 
China's large-scale arable land (more than $50 \mathrm{mu}$ in southern provinces and more than $100 \mathrm{mu}$ in northern regions) accounted for $28.6 \%$ of the total cultivated area of arable land in 2016 . The number of large-scale agricultural operation households nationwide reached 3.98 million households, while that of agricultural production and operation personnel of large-scale agricultural operation households reached 12.89 million. In short, by affecting the rural industrial structure and the combination of factors, the structural transformation of the dual economy causes the effect of agricultural productivity improvement in China and thus advances rural poverty alleviation.

As far as the effect of demographic change is concerned, the structural transformation of the dual economy means the non-agricultural transfer of the rural labor force and the ruralurban migration of the rural population. Whether the migrant workers go out individually or on a whole-family basis, they will impact the rural poverty alleviation in Chin due to the effects of demographic changes. Since the reform and opening-up, migrant workers have been the main form of non-agricultural transfer of the rural labor force in China. The structural changes in urban and rural areas represented by migrant workers have multiple characteristics. For example, both individual and family migration data of outgoing migrant workers are growing. According to the data provided by CEIC, the number of China's outgoing migrant workers increased from 140 million to 168 million between the period 20082014 while that of the migrant workers going out individually rose from 112 million to 132 million, and that of the migrant workers going out on a family basis increased from 29.59 million to 35.78 million. Comparatively, the migrant workers on a whole-family basis played a more critical role in expanding the urbanization rate. In addition, the outgoing migrant workers are distinctive from the ordinary rural labor force in terms of age, region and education level. The main characteristics of China's outgoing migrant workers are young and middle-aged, with relatively high education level, and mainly flowing to the eastern region. According to the data provided by CEIC, the average age of migrant workers in China was 40.2 years old in 2018. In particular, migrant workers aged $21-30,30-40$ and $40-50$ accounted for $25.2,24.5$ and $25.5 \%$, respectively. In 2018, the migrant workers with the education levels as junior high school, high school, junior college or above accounted for $55.8,16.6$ and $10.9 \%$. The education level of migrant workers was better than that of the overall farmers. In addition, the eastern coastal region was the main inflow of migrant workers. In 2017, the numbers of migrant workers in the Yangtze River Delta and the Pearl River Delta were 53.87 million and 47.22 million, respectively, the amounted number of which accounted for $58.8 \%$ of migrant workers that year.

Proceeding from the characteristics of migrant workers, we can see that China's urbanization rate had witnessed rapid growth after the reform and opening up. Based on the permanent population, the urbanization rate increased from 17.92 to $60.60 \%$ from 1978 to 2019, and the urbanization rate exceeded $50 \%$ for the first time in 2011 . After nearly one hundred years of structural changes, during the period 2003-2010, China's urban-rural relations finally took a revolutionary leap and entered the urban-rural China stage from rural China (Liu and Wang, 2018). According to the registered population, during the period 19802019 , the urbanization rate also increased from 16.64 to $44.38 \%$, and the rural population continued to decline with its proportion in the permanent population less than a half. This means that larger-scale social groups can share the growth fruits resulting from the urbanization and implies the government is better equipped to implement support and backfeeding policies for rural residents. Taking into account the group characteristics of migrant workers and the role of wage and salary in the income of farmers as the mainstay, rural laborers who migrate between urban and rural areas usually have a higher level of income, which to some extent provides a "screening" mechanism for identifying the rural poor people. That is, the groups who are relatively older, less educated and geographically restricted for social mobility are usually the key groups that need to be targeted and focused on by poverty 
CPE 4,1

alleviation policies. Under the prerequisite of the structural transformation of the dual economy and rural labor mobility, China has the conditions to more accurately identify the rural poor population and take more targeted poverty alleviation measures. According to the people registered as living in poverty in 2013, the basic situation of China's poor areas and the population status were as follows: 14 contiguous impoverished areas, 832 poor counties, 128,000 impoverished villages, nearly 30 million households, 70.17 million poor population (Li, 2018). Poverty Monitoring Report of Rural China 2019 also showed that according to the current national rural poverty standard, in 2018, the proportion of the poor people in the eastern, central and western regions accounted for $8.8 \%, 36.0 \%$ and $55.2 \%$ of the whole country' poor population, respectively. The poverty incidence of the elderly and children is relatively high. The households whose education levels were illiteracy, elementary school, junior high school, high school and above, their poverty incidences were $6.5 \%, 2.4 \%, 1.2 \%$ and $0.9 \%$, respectively. The migrant workers and the rural poor population have a vital group characteristic - the "mirror complementary" feature. Meanwhile, the dual economy's structural transformation makes poverty alleviation policies more targeted due to the effects of demographic changes.

In terms of the effect of financial resource allocation, since 1978, along with the effects of labor reallocation and agricultural productivity improvement caused by the structural transformation of the dual economy, China's economy has maintained a rapid growth trend. Economic growth has further led to a significant increase in national fiscal resource mobilization, providing robust support for targeting low-income people in the development process, especially the rural poor people, implementing financial transfer payments and increasing the supply of public goods. From 1978 to 2019, China's fiscal revenue rose from 113.226 billion yuan to 11.04 trillion yuan, an increase of 168.14 times over 42 years, which far exceeded the 14.07-time growth during the period 1950-1977. With the rural labor mobility in the context of the structural transformation of the dual economy, the poor in rural areas who cannot fully share the fruits of economic growth have been in great need of attention. In place of the backward social production, the problem of unbalanced and insufficient development has become the bottleneck of the central social contradiction in the new era. The unbalanced development between urban and rural areas and the inadequate development of agriculture and rural areas are in urgent need of response. In this context, China has not only improved the relationship between urban and rural areas by altogether abolishing agricultural taxes, implementing new rural cooperatives and new rural insurance, accelerating agricultural supply-side structural reforms and implementing rural revitalization strategies, but also implemented more targeted and more effective poverty alleviation policies with substantial growth in financial resources and changes in the allocation of financial resources as preconditions.

Since 2013, China has implemented a targeted poverty alleviation policy featuring "precise identification, precise assistance, precise management and precise assessment". Targeted poverty alleviation policies are inseparable from the effects of financial resource allocation. For example, according to Outline for Poverty Reduction and Development of China's Rural Areas (2001-2010), the poverty alleviation goal of "two no worries and three guarantees" has been expressly put forward - that the people living below the poverty line can be free from worries over food and clothing and have access to compulsory education, essential medical services and safe housing by 2020. The Fifth Plenary Session of the 18th Central Committee of the Communist Party of China proposed that by 2020, under the current standards in China, the rural poor population would shake off poverty, along with all impoverished counties removing their labels as poverty-stricken places and the overall regional poverty problem to be resolved. In this context, China's financial investment in solving rural poverty problems gradually reinforces. The average annual poverty alleviation investment in the poverty alleviation project by the central government was 5.84 billion yuan during the period 1986- 
$1993,17.74$ billion yuan during the period $1994-2000$ and 20.44 billion yuan during the period 2001-2010 (Zhang, 2007; Zhou and Tao, 2016). According to data released by the Ministry of Finance, the central government's special poverty alleviation funds were 27 billion yuan, 33.2 billion yuan, 39.4 billion yuan, 42.3 billion yuan, 46.09 billion yuan, 66.095 billion yuan, 86.095 billion yuan, 106.095 billion yuan and 126.095 billion yuan from 2011 to 2019 , respectively, an average of 51.809 billion yuan per year. Financial support has not only prominently improved the level of infrastructure and public service supply in rural areas, especially in povertystricken areas, but has also significantly led to changes in the income status of farmers, especially poor rural populations. From 2013 to 2019, farmers' per capita net transfer income increased from 1,647.53 yuan to 3,298.00 yuan, with the proportion in per capita disposable income rising from 17.47 to $20.59 \%$. According to Poverty Monitoring Report of Rural China 2019 , in 2018, of the per capita disposable income of farmers in poverty-stricken areas, net transfer income accounted for $26.21 \%$, and the low-income group and lower-middle-income group took up 42.48 and $30.91 \%$. The proportions of net transfer income of the rural population, rural poor population and the low-income population in poor rural areas have increased respectively, indicating that China's structural transformation of the dual economy has indeed produced the effect of financial resource allocation. The poverty alleviation policies based on budgetary transfer payments have played a driving role in the large-scale poverty alleviation in rural areas.

\section{The "second half" of China's poverty alleviation strategy: reconnecting with the structural transformation of the urban-rural dual economy}

Since 1978, China has created a "miracle" of poverty alleviation. Consistent with the logical deduction, China's structural transformation of the urban-rural dual economy has produced the effects of labor reallocation, agricultural productivity improvement, demographic changes and fiscal resource allocation. The associated economic growth and poverty alleviation policies have formed monumental poverty alleviation achievements. The structural transformation of the dual economy is a primary driving force for China's poverty alleviation. Remarkably, whether the structural transformation of the dual economy can be carried out and whether an organic combination of economic growth and poverty alleviation policies can form are related to the specific social structure and institutional arrangements. China's structural transformation of the dual economy can achieve significantly better poverty alleviation results than other countries simply because China's social system is conducive to the full play of the above four effects. China's socialist system is essentially characterized by the liberation and development of productive forces and the realization of common prosperity. The leadership of the Communist Party of China provides a political basis and organizational guarantee for mobilizing various forces to achieve development goals. Before the reform and opening up, China relied on state power to restore economic order and formulated an independent and complete industrial system. After the reform and opening up, to solve the bottleneck problem of backward social production, that is, the principal social contradiction, China implemented a reform and opening-up strategy. In the context of economic system transformation, the rural people's commune system has shifted to a household contract responsibility system with remuneration linked to output. The unified purchase and sale of agricultural products have moved to market-oriented circulation. The employment regulation of the household registration system has begun to relax gradually. The ownership of enterprises has also shifted from the unitary adoption of public ownership to multiple forms of ownership developing side by side. The transformation of the economic system has created hundreds of millions of microeconomic entities in urban and rural areas also enabled them to conduct commodity exchange and flow of factors between urban and rural areas based on the price mechanism. This provides an institutional condition 
CPE 4,1

104

for the structural transformation of the dual economy and the generation of poverty alleviation effect. Similarly, under the premise of economic growth, the socialist system has made China pay close attention to the unbalanced, uncoordinated and unsustainable development, turned the growth-oriented development concept into "innovative, coordinated, green, open and shared" development concepts, and resolve the distribution issues through the government's macro-control and public product supply functions. Meanwhile, the socialist system also enables China to use organizational advantages like "the party secretaries at five levels engaged in poverty alleviation" to implement targeted poverty alleviation policies effectively. In brief, the structural transformation of the dual economy forms a "miracle" of poverty alleviation via four significant effects, and these effects are inseparable from China's socialist system and the transformation of the economic system after reform and opening up.

The structural transformation of the dual economy since the reform and opening-up has created a "miracle" in poverty alleviation in China. By the end of 2020, China will achieve the goal of all-out poverty alleviation, and the problem of absolute poverty in rural areas will be entirely resolved. However, Wang and Liu (2018) argued that the resolution of the absolute poverty problem under the existing standards did not mean eradication of the poverty problems or the end of anti-poverty. Instead, it only indicates that the poverty alleviation strategy will stand at a new starting point with new goals. This is because some of the poverty-stricken population are strongly dependent on external resources, and the function of pumping fresh blood into these regions and the long-term for poverty alleviation formed in light of their own conditions are not solid enough, which implies the vulnerability of poverty alleviation and risk of returning to poverty [1]. China's current poverty line was per person's annual income of 2,300 yuan based on the 2010 constant price, which is lower than the poverty line for lower-middle-income countries ( $\$ 3.2$ per person per day, in 2011 PPP dollars) and a poverty line of upper-middle-income countries ( $\$ 5.5$ per person per day, in $2011 \mathrm{PPP}$ dollars) defined by the World Bank. According to Ye and Yin (2019), China's current poverty standard is at a lower-middle level, with a large gap with the poverty standard of developed countries, which is not even relatively high compared to middle-income countries. Based on the current national standards, after solving absolute poverty in 2020, China will shift the focus of the poverty alleviation strategy to a more complex problem of relative poverty. For solving relative poverty, it is necessary to change the poor population identification mechanism and highlight the endogenous capabilities and long-term tools of micro-subjects. The solution to the problem of absolute poverty cannot be directly transplanted into the solution of relative poverty. Furthermore, China's structural transformation of the dual economy has also put forward higher requirements for poverty alleviation strategies in the new era. For example, with the non-agricultural flow of rural labor and the increased urbanization rate, the distribution structure of the poor population in urban and rural areas are changed, and the issue of relative urban poverty has begun to become a new focus of poverty alleviation strategies. In rural areas, farmers have become increasingly differentiated with a widening income gap. Regarding the per capita net income of farmers from 2000 to 2013, the income gap between high-income households and low-income households widened from 6.47 times to 8.21 times; regarding the per capita disposable income of rural households from 2014 to 2019, the income gap between high-income households and low-income households widened from 7.41 times to 9.29 times. The aging rate in rural areas has rapidly increased and even exceeded that in cities. The proportion of the rural population aging 65 and over from 1997 to 2018 increased from 6.75 to $13.84 \%$. In 2018, with the aging rate of China being $11.9 \%$, the income gap widened and the aging rate increased rapidly in rural areas, which has brought new challenges for the rural poor population to form an endogenous impetus for poverty alleviation. 
With the victory in the battle of poverty alleviation and the construction of a moderately prosperous society in all respects in 2020 as the demarcation point, China will enter the "second-half" stage of the poverty alleviation strategy. Namely, with the stimulation of the endogenous power of micro-subjects as the main thread, the government's centralized assistance policies will be shifted to a more conventional and sustainable long-term mechanism to solve the relative poverty of urban and rural residents. In the new stage focusing on solving relative poverty, the poor population concentrated in the rural areas will be distributed to both urban and rural areas. In particular, due to institutional and individual factors, some migrant workers have difficulties integrating into cities in the short term, thus making them prone to become the relatively poor population in cities. That being said, the structural transformation of the dual economy still affects the effectiveness of poverty alleviation via the labor reallocation effect, agricultural productivity improvement effect, demographic change effect and fiscal resource allocation effect. The difference lies in the fact that in the phase of resolving relative poverty, the effect of labor redistribution occurs between urban and rural areas and also occurs between the registered population and the migrant population within cities. The targets of the fiscal resource allocation effect have also changed from the absolute poor population in rural areas to the relative poor population in urban and rural areas. The structural transformation of the dual economy and its impact on poverty alleviation is closely related to the transformation of the social system and economic system. To solve relative poverty, we should give full play to the potent institutional advantages of the socialist system and the CPC's leadership with the continuous reinforcement of the coordination between economic growth and poverty alleviation policies. Particularly, markets should play a decisive role in the allocation of resources to promote economic growth and form a solid foundation for poverty alleviation; the government should play its role better to encourage the pertinence, operability and effectiveness of poverty alleviation policies. In the "second-half" phase of the poverty alleviation strategy, rather than abandon or delay the structural transformation of the dual economy, China shall adjust and improve the government-market relationship and accelerate the deeper and broader transformation of the dual economy. This is a process of "reconnecting" the poverty alleviation strategies with the structural transformation of the dual economy and a process of responding to the new goal of poverty alleviation by accelerating the structural transformation of the dual economy.

In the new stage of resolving the relative poverty in urban and rural areas, to reconnect China's poverty alleviation strategies with the structural transformation of the dual economy, the following ideas and policy orientations can be considered. The first idea is to formulate the identification criteria for the poor groups dynamically. Identifying the relatively poor groups accurately is a prerequisite for China's poverty alleviation strategies in the new era. The relatively poor population is a concept that changes with the increase in overall household income and changes in income distribution. In terms of showing the poverty situation, the World Bank also proposes another method of poverty identification in addition to the three poverty lines of USD 1.9, 3.2 and 5.5: the per capita income (or consumption) level of the bottom $40 \%$ of the population, which can be regarded as the basis for identifying and judging the relatively poor population. According to this standard, China's relative poverty lines in 2013 and 2016 were USD 3.92 and 4.99 in 2011 purchasing power parity, respectively. Drawing on this thinking pattern, China can regard the per capita income of the lowest-income population (e.g. 30\%) or a certain percentage of the median per capita income (e.g. $40 \%$ ) as the relative poverty line. This helps to identify relatively poor groups and form a systematic poverty alleviation plan for balanced urban and rural development. The second idea is to enhance the human capital of the poor population as the core mechanism for poverty alleviation. To solve relative poverty, we should intensify the endogenous ability of the poor, and human capital is the main source of 
CPE 4,1

106

the endogenous ability of the poor. To this end, China should further enhance its investment in education and training for low-income groups. Moreover, based on consolidated achievements of basic education, it is also necessary to place vocational education and training in a more important position and provide more policy support for the low-income population to participate in vocational education and training. Besides, we should also further enhance the mobility of laborers and population and promote the increase of population mobility between urban and rural, inter-city and rural areas based on informatization and infrastructure construction so that laborers can have better chances of being allocated to the fields with higher evaluation for them. In this sense, accelerating the structural transformation of the dual economy and urging the transfer of rural labor from a scale-oriented pattern to a quality-oriented pattern will still be able to facilitate China's poverty alleviation performance. The third point is to deepen the household registration and financial system's reform to promote the two-way flow of urban and rural factors. When the rural poor people move to the cities and engage in non-agricultural industries, they are likely to face relative urban poverty due to their difficulties fitting in. The focus of China's structural transformation of the dual economy should be changed from "getting out" of the rural areas to "retaining" in the cities. To this end, the reform of the household registration system should be accelerated to address the issue of "citizenization" of the rural population. Meanwhile, the initiative of loosening the conditions for the settlement in large cities and small- and medium-sized cities should also be sped up, with further exploration of the effective ways to reform the household registration system in megacities and super cities. The structural transformation of the dual economy means the nonagriculturalization of rural laborers and the extensive integration of urban factors and rural industries. For this purpose, the reform of factor marketization should be deepened. The protection of the property rights of factor owners should be strengthened, and urban capital, technology, management, information, data and so on should be encouraged to land in the rural areas so that the rural poverty problem can be solved based on improving the efficiency of rural element combination. The fourth point is to achieve an effective connection between the poverty alleviation strategies and the rural revitalization strategies with the land system reform as a carrier. The land system has a direct impact on rural economic development and poverty alleviation. In the future, rural areas may still be the places where relatively poor people are relatively concentrated. For solving rural relative poverty, it is necessary to combine a poverty alleviation strategy that emphasizes a longterm mechanism with a rural revitalization strategy that highlights sustainment. Thanks to this, it is required to accelerate the reform of separating the ownership rights, contract rights and management rights for contracted rural land, implement pertinent pilot programs, promote the reform in actual practice and speed up building a unified urban and rural construction land market. With the socialized allocation of land as a traction force, rural land is organically combined with capital, technology, information and other elements to improve the service industry functions of rural products and the level of the added value of products. This is a process of improving the living standards of the rural poor population and a process of industry thriving in the rural revitalization strategies. The fifth idea is to reinforce social security in poverty alleviation strategies. Relative poverty caused by individual factors may happen at any time. Poverty alleviation policies should prevent members of society from falling even to maintain their living at the survival level and becoming "dependent" on external resources at the same time. China should draw on the "Conditional Cash Transfers" (CCTs) commonly implemented in foreign countries and clarify that beneficiaries need to undertake certain family obligations and carry out their commitments to find work when receiving poverty relief (Zheng, 2019), which is important for avoiding the "reverse incentives" of the poverty alleviation policies and "welfarization" of the poverty alleviation resources. In addition, China should pay more attention to the 
urban-rural dual social structure, accelerate the transformation of the dual structure from the economic field to the social field, increase investment in agricultural and rural infrastructure and reinforce the supply guarantee of farmers' basic education, basic medical care, basic pensions and other public products, gradually increase the equalization degree of the allocation of urban and rural public products, enhance the protection function of social security for the poor population, thus effectively solving the problem of relative poverty in light of the coordination of the enhanced endogenous capacity and reinforced social security.

\section{Note}

1. In 2020, General Secretary Xi Jinping pointed out in his speech at the forum on securing decisive victory in poverty alleviation that according to the preliminary results from different regions, nearly 2 million people who had been lifted out of poverty were at risk of returning to poverty, and nearly 3 million of the marginalized population were at risk of becoming poor. Moreover, according to the "Poverty Monitoring Report of Rural China 2019", the proportion of rural laborers in povertystricken areas who received skills training was only $22.7 \%$ in 2018 , in which the proportions of laborers who received agricultural technology training and non-agricultural technology training were 18.2 and $11.7 \%$.

\section{References}

Cai, F. (2019), Zhongguo jingji fazhan de shijie yiyi [World Significance of China's Economic Development], China Social Sciences Press, Beijing.

Cheng, M.W., Jia, X.J. and Yu, N. (2018), "Nongcun laodongli zhuanyi dui zhongguo jingji zengzhang de gongxian (1978-2015): moxing yu shizheng [The contribution rate of rural labor transfer to economic growth of China (1953-2015): model and empirical study]", Guanli Shijie [Management World], Vol. 34 No. 10, pp. 161-172.

Department of Household Surveys National Bureau of Statistics of China (2019), Poverty Monitoring Report of Rural China 2019, China Statistics Press, Beijing.

Fan, S., D. and Jiang, K.Z. (2016), "Zhongguo nongcun jiating laodongli liudong de jianpin xiaoying yanjiu: jiyu CFRS shuju de weiguan zhengju [China's labor migration effects on alleviating poverty for rural household: micro evidence based on CFPS data]", Zhongguo Renkou kexue [Chinese Journal of Population Science], Vol. 30 No. 5, pp. 26-34.

Gao, F. (2019), Cong gelie dao ronghe: zhongguo chengxiang jingji guanxi yanbian de zhengzhi jingjixue [From fragmentation to integration: political economy of the evolution of China's urban-rural economic relationship], Fudan University Press, Shanghai.

Hao, D.M. (2016), "Nongcun laodongli zhuanyi dui zhongguo jingji zengzhang de gongxianlv [The contribution rate of agricultural labor force transfer to economic growth of China from 1953 to 2015]", Zhongguo nongcun jingji [Chinese Rural Economy], Vol. 32 No. 9, pp. 44-57.

Li, M. (2018), "Zhengfu, shichang, shehui: jingzhun fupin de zhixu weidu [Government, market and society: order dimension of targeted poverty alleviation]", Xueshujie [Academics in China], Vol. 33 No. 7, pp. 62-71.

Li, X.Y., Xu, J. and Yu, L.R. (2018), "Zhongguo jianpin sishi nian: jiyu lishi yu shehuixue de changshixing jieshi [China's 40 years of poverty reduction: an exploratory account from historical and sociological perspectives]", Shehuixue yanjiu [Sociological Studies], Vol. 33 No. 6, pp. 35-61.

Liu, S.Y. and Wang, Y.G. (2018), "Cong xiangtu zhongguo dao chengxiang zhongguo: zhongguo zhuanxing de xiangcun bianqian shijiao [From native rural china to urban-rural China: the transition perspective of China transformation]", Guanli shijie [Management World], Vol. 34 No. 10, pp. 128-146. 
CPE 4,1
Lu, H.Y. and Du, Y.X. (2019), "Zhongguo caizheng zaifenpei yu jianpin xiaoying de shuliang cedu [Quantitative measurement of fiscal redistribution and poverty reduction effect in China]", Economic Research Journal, Vol. 54 No. 2, pp. 34-36.

National Bureau of Statistics of China (2019), "China statistical Yearbook 2019”, available at: http:// www.stats.gov.cn/tjsj/ndsj/2019/indexch.htm (accessed 9 May 2020).

Poverty Alleviation Research Group of National Institute of Development Strategy at Wuhan University (2019), "Yi chanye fazhan baozhang pinkun renkou wending tuopin de zhanlve sikao [Strategic thinking on ensuring the stability of poverty-stricken population out of poverty through industrial development]", Zhongguo renkou kexue [Chinese Journal of Population Science], Vol. 33 No. 6, pp. 2-14.

Ravallion, M. and Chen, S.H. (2007), "China's (uneven) progress against poverty", Jingji yanjiu [Journal of Development Economics], Vol. 82 No. 1, pp. 1-42.

Tan, X.W. (2018), "Pinkuncun de neisheng fazhan yanjiu: wanbei xincun jingzhun fupin kaocha [The endogenous development of a poor village: an investigation on targeted poverty alleviation in an average poor village]", Zhongguo nongcun jingii [Chinese Rural Economy], Vol. 34 No. 11, pp. $48-63$.

The State Council of the People's Republic of China (2011), "Outline for poverty reduction and development of China's rural areas (2001-2010)", available at: http://www.gov.cn/jrzg/2011-12/ 01/content_2008462.htm (accessed 9 May 2020).

Wang, S.G. (2008), "Zai fazhanzhong zhansheng pinkun: dui zhongguo 30 nian daguimo jianpin jingyan de zongjie yu pingjia [Beating poverty by means of development: a summary and evaluation of the experiences of China's large-scale reduction of poverty in the past 30 years]", Guanli shijie [Management World], Vol. 24 No. 11, pp. 78-88.

Wang, Z.W. (2017), "Zhongguo nongcun fanpinkun jixiao de tuidong yinsu cedu ji fenjie: 1978-2014 [Measurement and decomposition of the promoting factors on China's rural anti-poverty performance: 1978-2014]", Caimao jingji [Finance and Trade Economics], Vol. 38 No. 9, pp. 96-110.

Wang, S.G. (2018), “Zhongguo 40 nian daguimo jianpin: tuidong liliang yu zhidu jichu [China's largescale poverty reduction: main driving forces and institutional foundation]", Zhongguo renmin daxue xuebao [Journal of Renmin University of China], Vol. 32 No. 6, pp. 118-119.

Wang, S.G. (2020), "Zhongguo fupin jixiao yu jingzhun fupin [Poverty alleviation performance of China and targeted poverty alleviation]", Zhengzhi jingji pinglun [China Review of Political Economy], Vol. 18 No. 1, pp. 130-148.

Wang, C. and Liu, J.X. (2018), "Zhongguo fanpin gongzuo sishinian lishi yanjin: jiyu 1978-2018 zhongguo fanpinkun zhengce de lianghua fenxi [The evolution of Chinese anti-poverty work over the past 40 years: an quantitative analysis based on China's anti-poverty policies (19792018)]", Zhongguo nongcun jingji [Chinese Rural Economy], Vol. 34 No. 12, pp. 2-18.

Wang, L.Y. and Xu, M. (2019), "Zhongguo jingzhun fupin zhengce de jianpin xiaoying yanjiu: laizi zhunziran shiyan de jingyan zhengju [Research on the effect of poverty reduction of targeted poverty reduction policy: empirical evidences from Quasi natural experiment]", Tongji yanjiu [Statistical Research], Vol. 36 No. 12, pp. 15-26.

Wang, C., Wan, G.H. and Wu, W.Z. (2020), "Zhongguo jianpin zhanlve zhuanxing jiqi mianlin de tiaozhan [Transformation of China's poverty-reduction strategy and related challenges]", Zhongguo gongye jingji [China Industrial Economics], Vol. 37 No. 1, pp. 5-23.

Xing, C.J. and Li, X.Y. (2018), "Chaoyue jiegou yu xingdong: zhongguo tese fupin kaifa daolu de jingyan fenxi [Beyond structure and action: an empirical analysis on the road to poverty alleviation with Chinese characteristics]", Zhongguo nongcun jingji [Chinese Rural Economy], Vol. 34 No. 11, pp. 32-47.

Ye, X.Q. and Yin, H.D. (2019), "Cong xiaochu juedui pinkun dao huanjie xiangdui pinkun: zhongguo jianpin licheng yu 2020 nianhou de jianpin zhanlve [From eliminating absolute poverty to 
alleviating relative poverty: China's history of poverty reduction and poverty reduction strategies after 2020]", Gaige [Reform], Vol. 34 No. 12, pp. 5-15.

Zhang, L. (2007), Zhongguo fupin kaifa licheng (1949-2005 nian) [The course of poverty reduction in China (1949-2005)], China Financial \& Economic Publishing House, Beijing.

\section{China's} poverty alleviation

Zhang, Q.H. and Zhou, Q. (2019), "Jingzhun fupin zhengce xiaoguo pinggu: shouru, xiaofei, shenghuo gaishan he waichu wugong [Policy evaluation of China's targeted poverty alleviation: income, expenditure, life improvement and migrant work]", Tongji yanjiu [Statistical Research], Vol. 36 No. 10 , pp. 17-29.

Zheng, B.W. (2019), "Hou 2020 shidai jianli wending tuopin changxiao jizhi de sikao [Reflection on establishing a permanent mechanism for poverty alleviation after 2020]", Hongguan jingji guanli [Macroeconomic Management], Vol. 35 No. 9, pp. 17-25.

Zhou, M.H. and Tao, R. (2016), "Shichang haishi zhengfu: pinggu zhongguo nongcun jianpin zhengce [Market or government: evaluating China's rural poverty reduction policy]", Guoji jingji pinglun [International Economic Review], Vol. 21 No. 6, pp. 63-76.

\section{Further reading}

Zhang, G.W., Wang, Q. and Zhang, R. (2018), "Zhongguo nongye laodongli zhuanyi de jianpin xiaoying yanjiu [The research of the poverty reduction effect of agricultural labor migration in China]", Zhongguo renkou kexue [Chinese Journal of Population Science], Vol. 32 No. 4, pp. 18-29.

\section{Corresponding author}

Fan Gao can be contacted at: gaofan@fudan.edu.cn

For instructions on how to order reprints of this article, please visit our website:

www.emeraldgrouppublishing.com/licensing/reprints.htm

Or contact us for further details: permissions@emeraldinsight.com 